\title{
A new Denisiella Folsom and Mills, 1938 (Collembola: Sminthurididae) from Colombia
}

\author{
MARCELA OSPINA ${ }^{1} \&$ JOSÉ G. PALACIOS-VARGAS ${ }^{2,3}$

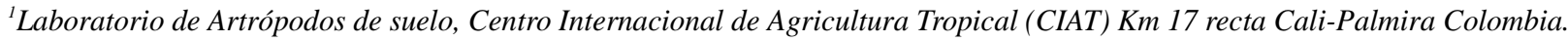 \\ E-mail: ciat-artrosuelo@ciat.cgiar.org \\ ${ }^{2}$ Laboratorio de Ecología y Sistemática de Microartrópodos, Departamento de Ecología y Recursos Naturales, Facultad de Ciencias, \\ UNAM. 04510 México, D. F. \\ E-mail:jgpv@hp.fciencias.unam.mx \\ ${ }^{3}$ Corresponding author
}

\begin{abstract}
Denisiella colombiana sp. nov. is described and illustrated from Colombia. Males and females are studied. Two keys for the species of the world are included, one for males and one for females.
\end{abstract}

Key words: new species, sexual dimorphism, chaetotaxy

\section{Introduction}

Denisiella Folsom and Mills, 1938 - a genus of the family Sminthurididae-is remarkable because of its extraordinary sexual dimorphism. Till now only eight valid and two unnamed species (Bellinger et al. 19962008) belong to this genus.

The fauna of Collembola from Colombia is very poorly known. The knowledge base was broadened through a recent study by the senior author on species associated with agricultural soils (Ospina et al. 2004). Beyond that, there is only one contribution to taxonomy (Palacios-Vargas \& Peñaranda 2005).

The eight named species of Denisiella from the world are: D. lithophila Snider, 1988 (from United States of America); D. maesorum Palacios-Vargas, 1995 (Nicaragua), D. nayarita Palacios-Vargas \& Bernava, 1999 (Mexico), D. ramosa (Folsom, 1932) (Hawaii), D. seurati (Denis, 1925) (French Polynesia), D. serroseta (Börner, 1908) (South Africa) and D. sexpinnata (Denis, 1931), (Costa Rica) and D. diomedesi (Panama), which is the most recent description by the junior author (Palacios-Vargas, 2007).

A new species of Denisiella based on Colombian specimens of both sexes is described here. Chaetotaxy of male antenna follows the nomenclature of setae established by Massoud and Betch (1972).

Abbreviations: Ant. I-IV, antennal segments I-IV.

\section{Denisiella colombiana sp. nov.}

Figs 1-14

Description. Male. Length $600 \mu \mathrm{m}(\mathrm{n}=12)$. Body dark purple and furcula almost transparent. Legs and antennae with purple pigment at their bases. $6+6$ pigmented eyes.

Antennae classically bent as in all Sminthurididae males, elbowed between Ant. II and III. Ratio of antennal segments about 1:1.1: 0.47:0.69. Ant. I with 7 setae, two of them very small and thin. Ant. II with 20 
setae, five very thick, one microseta, one sensilla, two trichobothria (Tra1, Tra2) one microsensillum, and modified setae b1-6 on the same tubercle (Fig. 1). Ant. III with 9 setae, three setulae, one trichobothrium, three spines one ventral microsensillum and antennal organ with a pair of oval separate microsensilla (Fig. 1). Seta c1 lamellate, c2 rounded and lamellate, seta c3 as one large spine; Ant. IV simple, elliptical with about 40 setae, olfactory setae very difficult to distinguish. Chaetotaxy of the head (Fig. 2), with two spine-like setae (in middle line of anterior part).

Leg I: coxa with one seta, trochanter with three setae; femur with 11; tibiotarsus basally on the outer side with four big organs, bladder-like, thickwalled, and highly elevated (Fig. 3), about 30 setae, and two microsetae. Leg II: coxa with one seta and one spine; trochanter with three setae; femur with 11 setae, two of them much longer; tibiotarsus with 36 setae, two oval organs and one stout thicker dorsal seta and one cylindrical organ (Fig. 4). Leg III: coxa $(44 \mu \mathrm{m})$ with two setae and one spine; trochanter $(53 \mu \mathrm{m})$ with two setae, one microsetae and one small spine; femur $(91 \mu \mathrm{m})$ with 10 setae and one microseta, tibiotarsus $(212 \mu \mathrm{m})$ with four stout and coarsely serrate spine-like setae, 26 setae and three oval organs; pretarsus with one setae on each side. Unguis $(33 \mu \mathrm{m})$ without tunica and with one small inner tooth; unguiculus $(17 \mu \mathrm{m})$ with short filament not surpassing the unguis. Tibiotarsal organ absent (Fig. 5).

Thoracic segmentation not evident. Dorsal chaetotaxy of small abdominal segment with thick setae. Ventral tube with $1+1$ setae. Tenaculum, corpus with two setae, basal appendix and three teeth. Genital and anal segments ankylosed into a single mass Genital plate of the male with one pregenital seta and $4+4$ eugenital setae. Lateral anal valves with two serrate setae each (Fig. 6). Manubrium with seven pairs of setae, one of them longer (Fig. 7). Dens with 42 posterior setae, two of them very long, and some of the internal ones thicker (Fig. 8); anterior surface with the formula 3, 3, 3, 3, 2, 1, 1, 1. Mucro with two lamellae, the inner serrate, with 17-19 serrations, outer lamella smooth, one mucronal outer seta. Length of manubrium $76 \mu \mathrm{m}$, dens $178 \mu \mathrm{m}$, and mucro $76 \mu \mathrm{m}$, ratio as 1: 2.3:1. Maximum length $(\mu \mathrm{m})$ of setae on head 34 , body 44 , dens 34, tibiotarsus 31.

Female. Length 1,094 $\mu \mathrm{m}(\mathrm{n}=7)$. Body dark purple. Legs, antennae and furcula light purple. $6+6$ pigmented eyes.

Antennae not elbowed between Ant. II and III. Ratio of antennal segments about 1: 1.2: 1.6 : 2.5 Ant. I with 5 setae (Fig. 9). Ant. II with 12 setae. Ant. III with 13 setae and the antennal organ with a pair of oval separate microsensilla. Ant. IV simple, elongated with about 45 setae, olfactory setae impossible to distinguish. The chaetotaxy of the head (Fig. 10), only with thin setae.

Leg I: coxa with one seta; trochanter with three setae; femur with 11; tibiotarsus with about 30 setae, two oval organs and one serrate setae. Leg II: coxa with one seta and one spine; trochanter with three setae; femur with 12 setae, two of them much longer (Fig.11); tibiotarsus with 36 setae and two microsetae. Leg III: coxa $(56 \mu \mathrm{m})$ with 2 setae, one microseta and one small spine; trochanter $(69 \mu \mathrm{m})$ with two setae, one microsetae and one small spine; femur $(94 \mu \mathrm{m})$ with 10 setae and one microseta; tibiotarsus $(225 \mu \mathrm{m})$ with five stout and coarsely serrate spine-like setae, 26 setae and two oval organs; pretarsus with one setae on each side. Unguis $(52 \mu \mathrm{m})$ without tunica and with one small inner tooth; unguiculus $(44 \mu \mathrm{m})$ with long filament surpassing the unguis. Tibiotarsal organ absent (Fig. 12).

Thoracic segmentation not evident. Dorsal chaetotaxy of small abdominal segment with three pairs of serrate setae (Fig. 13). Ventral tube with $1+1$ setae. Tenaculum, corpus with two setae, basal appendix and three teeth. Genital and anal segments ankylosed into a single mass. Manubrium with seven pairs of setae, one of them longer. Dens with 42 posterior setae, two of them very long (Fig. 14), anterior surface with the formula 3, 3, 3, 3, 2, 1, 1, 1. Mucro with two lamellae, inner lamella serrate, with about 23 serrations, outer lamella smooth, with one mucronal outer seta (Fig. 14). Length of manubrium $76 \mu \mathrm{m}$, dens $227 \mu \mathrm{m}$, and mucro $104 \mu \mathrm{m}$, their ratio as 1: 2.9: 1.3 . Maximum length $(\mu \mathrm{m})$ of setae on head 45, body 52, dens 42, tibiotarsus 43.

Type material. Holotype male, 11 paratypes males, 7 paratypes females, all slides-mounted, preserved in Laboratorio de Artrópodos de suelo, Centro Internacional de Agricultura Tropical Cali, Colombia. 
Type locality. Colombia: Tolima: Espinal, Nataima (4 $\left.{ }^{\circ} 9^{\prime} \mathrm{N} ; 7^{\circ} 53^{\prime} \mathrm{W}\right)$, collected between 16 April and 1 June 2004 (12 males and 5 females). From pitfall traps, maize field, G. Fabio Velez coll.

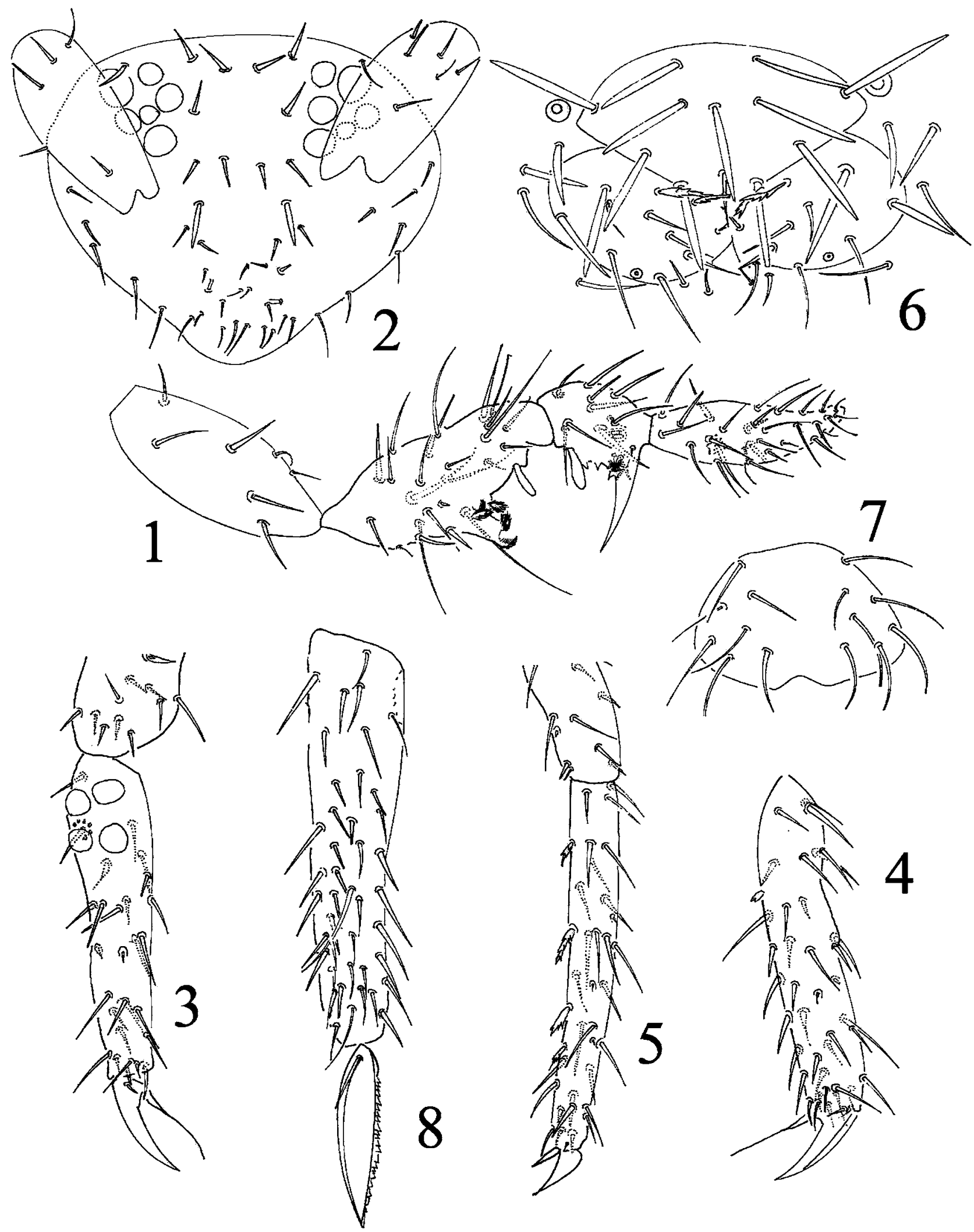

FIGURES 1-8. Denisiella colombiana sp. nov., male: 1, right antenna; 2, cephalic chaetotaxy; 3, tibiotarsus I; 4, tibiotarsus II; 5, femur and tibiotarsus III; 6, posterior chaetotaxy of Abd. VI; 7, manubrium, posterior view; 8 , chaetotaxy of right dens, anterior view. 


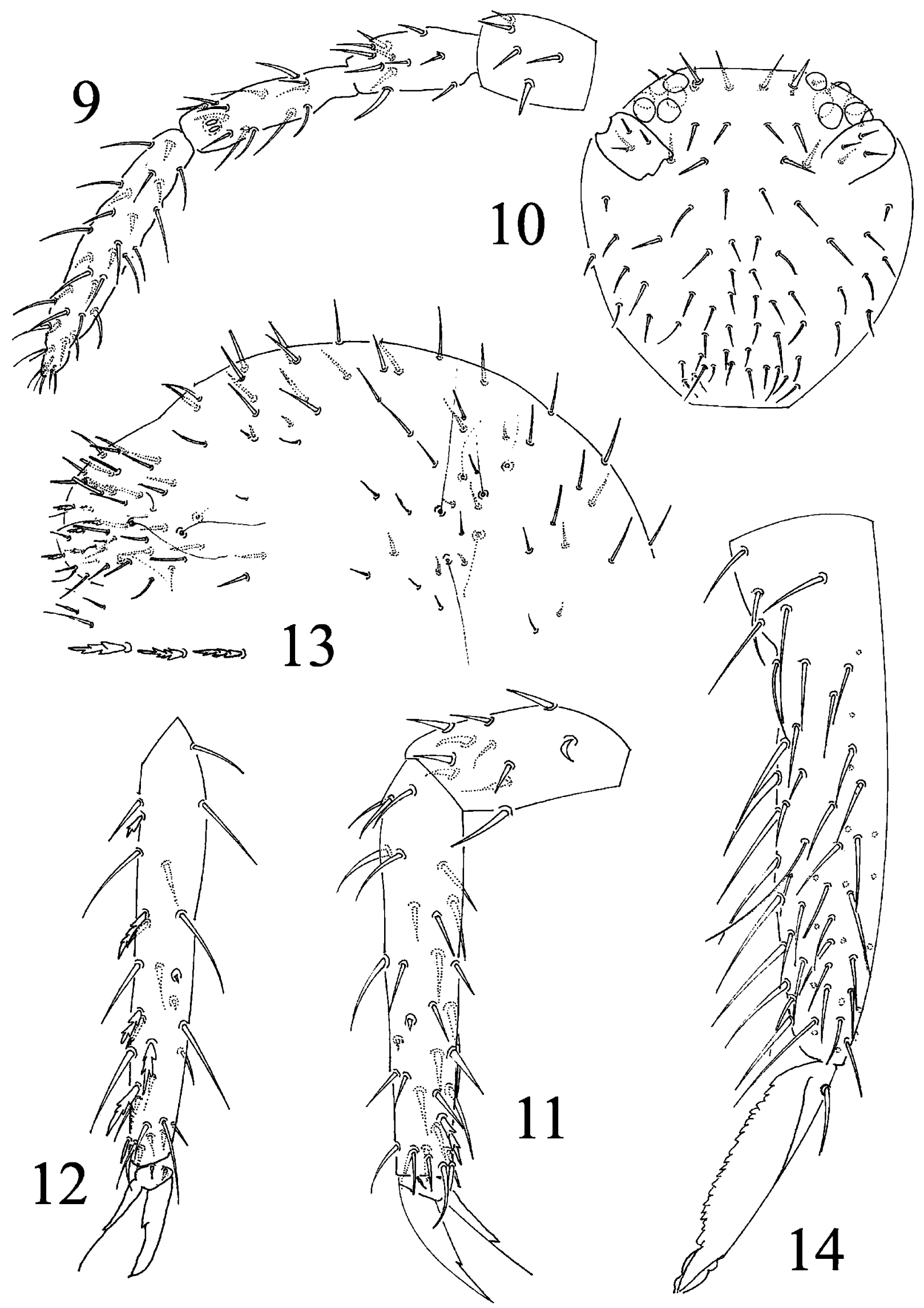

FIGURES 9-14. Denisiella colombiana sp. nov., female: 9, left antenna; 10, cephalic chaetotaxy; 11, femur and tibiotarsus II; 12, tibiotarsus III; 13, great and small abdomen in lateral view; 14, dens and mucro, latero-dorsal view. 
Other locality. Meta, Villavicencio, collected on May 7, 2004 (2 females). From pitfall traps, maize field, G. Fabio Velez coll.

Etymology. This species is named after the country of the type locality.

Discussion. The four organs on tibiotarsus I, apparently found in males of all species belonging to the genus Denisiella, are relatively large. The modified seta on tibiotarsus II is cylindrical, something very different from other species.

In males, the structures on Ant. II and III of D. colombiana sp. nov. are similar to $D$. diomedesi, but $D$. colombiana sp. nov. has three spines on Ant III. The number of normal setae on all antennal articles is less than in D. maesorum and D. diomedesi. The four bladder-like organs on tibiotarsus I of the new species are larger than in other species.

In females, the general morphology is similar to D. sexpinnata and D. ramosa. The difference is in the eyes number, $6+6$ in $D$. colombiana sp. nov. and $8+8$ in $D$. sexpinnatus, in addition $D$. colombiana sp. nov. is missing the serrate setae on tibiotarsus II, which are present in D. sexpinnatus and D. ramosa.

\section{Keys to the identification of world Denisiella species}

MALES. All males have antennae highly modified.

1 Eyes $8+8$

D. ramosa

- $\quad$ Eyes 6+6 2

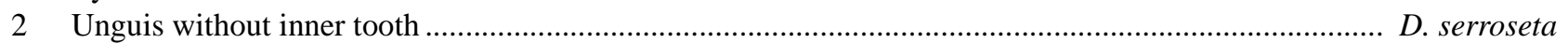

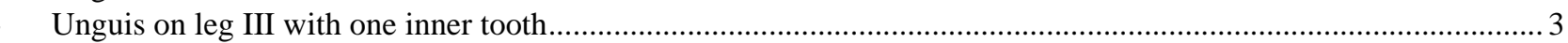

3 Tibiotarsus III with 3 serrate setae ...................................................................................................... D. lithophila

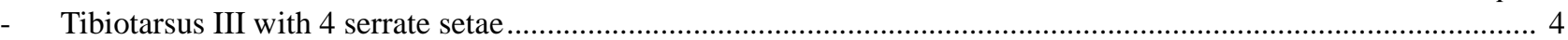

4 Tibiotarsus I with four large bladder-like organs......................................................... D. colombiana sp. nov.

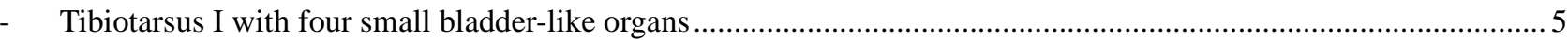

5 Head with an special organ formed by a basal insertion and four ciliated setae on the same alveolus (females

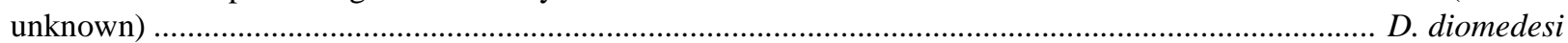

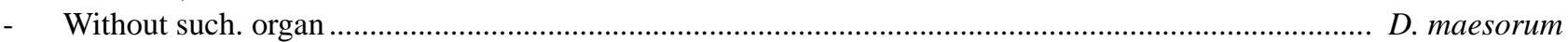

FEMALES. All females have normal antennae.

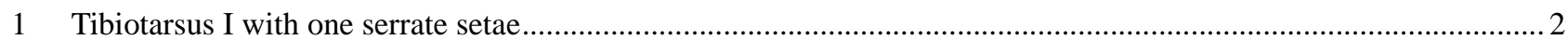

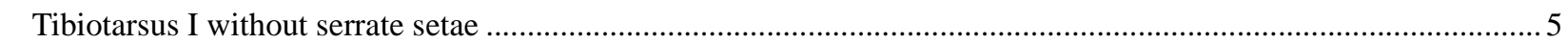

2 Unguis without inner tooth (males unknown) .......................................................................... D. nayarita

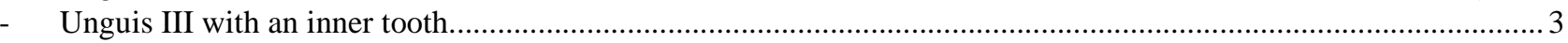

3 Tibiotarsus III with 4 serrate setae ................................................................................... D. maesorum

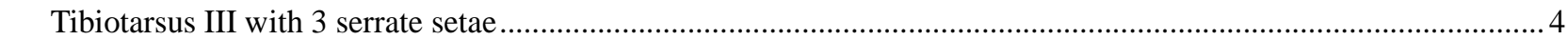

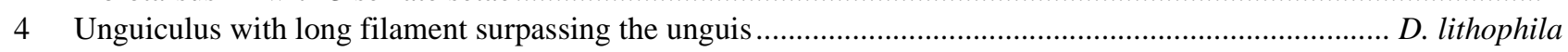

Unguiculus with filament shorter than unguis............................................................................... D. serroseta

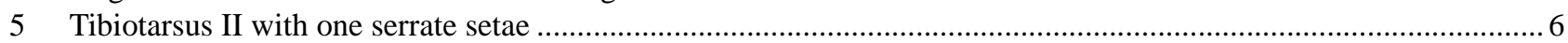

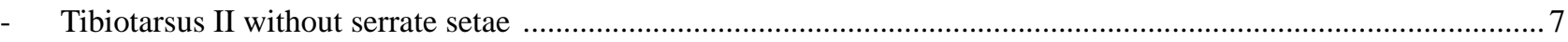

6 Anal valves with $3+3$ serrate setae (males unknown) .......................................................... D. sexpinnatus

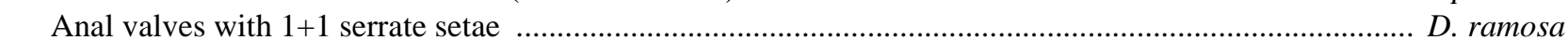

7 Anal valves with $3+3$ serrate setae ................................................................................. D. colombiana sp. nov.

- $\quad$ Anal valves without serrate setae (males unknown) .......................................................................... D. seurati 


\section{Acknowlegment}

The manuscript was kindly reviewed by Dr. Daniel C. Peck, Professor Assistent of the University of Cornell, New York, USA. MS. Arturo García Sánchez, Faculty of Sciences, UNAM, México, kindly prepared the final figures of the new species.

\section{References}

Bellinger, P.F., Christiansen, K.A. \& Janssens, F. (1996-2008) Checklist of the Collembola of the World. Available from: http://www.collembola.org (Date of last access 18.03.2009).

Börner, C. (1908) Collembolen aus Südafrika nebst einer Studie über die I. Maxille der Collembolen. In: L. Schultze Forschungsreise im westlichen und zentralen Südafrika, Denkschriften medicinisch-naturwissenschaftlichen Gesellschaft, Jena, 13, 53-68.

Denis, J.R. (1925) Sur les Collemboles du Muséum de Paris (2ème partie). Annales de la Société Entomologique de France, 94, 261-290.

Denis, J.R. (1931) Collemboles de Costa Rica avec une contribution au espècies de l'orde. Contributio alla conoscenza del "MICROGENTON" di Costa Rica, II. Bollettino del Laboratorio de Zoologia in Portici, 25, 69-170.

Folsom, J.W. (1932) Hawaiian Collembola. Proceedings of the Hawaiian Entomological Society, 8, 51-92.

Folsom, J.W. \& Mills, H.B. (1938) Contribution to the knowledge of the genus Sminthurides Börner. Bulletin of the Museum of Comparative Zoology, Harvard, 82, 231-274.

Massoud, Z. \& Betsch, J.-M. (1972) Étude sur les insectes collemboles. 2. Les caractères sexuels secondaires des antennes des Symphypleones. Revue d'écologie et de Biologie du Sol, 9, 55-97.

Ospina, C.M., Rodriguez, J., Mojocoa, M. \& Peck, D. (2004) Taxonomy of the springtails (Collembola) Associated with cotton and maize of the Valle del Cauca, Colombia. In CIAT (Centro Internacional de Agricultura Tropical). Annual Report Project PE-1. Integrated Pest and Disease Management in Major Agroecosystems. CIAT , Cali, Colombia, pp. $98-112$

Palacios-Vargas, J.G. (1995) A new species of Denisiella (Collembola: Sminthurididae) from Nicaragua. Revista Nicaraguense de Entomología, 32, 25-33.

Palacios-Vargas, J.G. (2007) A new species of Denisiella (Collembola: Sminthurididae) from Panama and new records for $D$. sexpinnata (Denis, 1938), Zootaxa, 1638: 63-68.

Palacios-Vargas, J.G. \& Bernava, V. (1999) A new Mexican species of Denisiella (Collembola: Sminthuridae). Journal of the Kansas Entomological Society, 72, 447-450.

Palacios-Vargas, J.G. \& Peñaranda-Parada, M.R. (2005) Two new species of Paranura (Collembola: Neanuridae) from Colombia and Mexico. Journal of the Kansas Entomological Society, 78, 308-314.

Snider, R.J. (1988) Denisiella lithophila, a new species from a granite outcrop in Georgia (Collembola: Sminthurididae). The Florida Entomologist, 71, 124-129. 